\title{
APLICAÇÃO DE DASHBOARDS PARA MONITORAMENTO DE INDICADORES DA DESEMPENHO EM UMA EMPRESA DO RAMO ALIMENTÍCIO
}

\author{
Vinicius Neumann Lins da Costa (UFCG) linsvcz@gmail.com \\ Daniel Augusto de Moura Pereira (UFCG) danielmoura@ufcg.edu.br
}

\section{Resumo}

O atual cenário das organizações produtivas estabelecem um elevado fluxo de dados, exigindo das mesmas agilidade e eficácia, sendo necessário que essas informações sejam transmitidas no momento certo, da maneira certa para o usuário certo, com o objetivo de se obter resultados acurados. Neste sentido, a criação de painéis "self-service", com a utilização de ferramentas de Business Intelligence (BI), trazem nitidez no olhar sobre a leitura de dados, possibilitando o acompanhamento e exibição de indicadores chave de performance (KPIs). Logo, todas as informações que primeiramente pareciam confusas, passam a serem entregues em gráficos, tabelas e imagens de forma simples, possibilitando uma melhor usabilidade, e, portanto, melhorando à tomada de ação. Diante disto, o presente trabalho teve como objetivo a utilização de dados secundários de uma empresa produtora de sorvetes do estado do Pernambuco para criação de painéis de controle enfatizando a gama de produtos vendidos e o faturamento mensal no intervalo de seis meses com a utilização do software Power BI para, posteriormente, serem analisados em tempo real de acordo com a necessidade da organização e, assim, ganhar vantagem competitiva frente aos concorrentes.

Palavras-Chaves: Fluxo de dados; Dashboards; Business Intelligence; Indicadores chaves de performance; Power BI.

\section{Introdução}

O ambiente de negócios no qual as empresas operam atualmente está se tornando cada vez mais complexo em virtude de um crescimento exponencial de dados que exigem, das empresas, rapidez nas tomadas de decisões, sejam elas estratégicas, táticas e operacionais com o objetivo de obter resultados e, assim, ganhar vantagem competitiva frente aos concorrentes. Por meio dessa perspectiva, a informação passa a não ser apenas um emaranhado de números, 
mas sim, um recurso e uma condição de produtividade crucial para a sobrevivência de qualquer organização. Ou seja, a busca por informações de qualidade tornou-se inevitável para a obtenção de soluções.

De acordo com a pesquisa "The 2018 Global Data Management Benchmark Report", divulgada pela Experian e realizada com profissionais do Brasil, Estados Unidos, Inglaterra e Austrália, aponta que 91\% das empresas brasileiras consideram os dados internos para definirem suas estratégias de negócios. Além disso, recentemente, a pesquisa mencionou que "as organizações afirmaram suspeitar de que quase um terço de seus dados era impreciso e $70 \%$ dizem que não têm controle direto sobre os dados que eles precisam para impactar os objetivos estratégicos” (The 2019 Global Data Management Benchmark Report).

Do exposto acima, percebe-se que as organizações precisam observar que não adianta somente armazenar informação, se não reunir esforços para selecioná-la e utilizá-la de forma organizada e estruturada, como recurso para gerar vantagem e competitividade no mercado. Nesse contexto, surge a Business Intelligence (BI), que é um conjunto de ferramentas que possibilita criar, acessar e manipular dados de forma interativa e oferecer aos gestores e analistas de negócios uma análise adequada na condição de servir como base ao refinamento e aprimoramento das atuais decisões (TURBAN, 2009).

Logo, o objetivo deste trabalho é implantar a Business Intelligence, a partir do software Power $B I$, para monitoramento da produção, destacando a variedade produtiva e custos de uma empresa produtora de sorvetes do estado do Pernambuco.

\section{Referencial Teórico}

\subsection{Business Intelligence}

Laudon (2014, p. 367) Business Intelligence, é um termo usado por fornecedores de hardware e software e consultores de tecnologia da informação para descrever a infraestrutura para armazenamento, integração, elaboração de relatórios e análise de dados que vêm do ambiente empresarial.

Já Para Sezões, Oliveira e Baptista (2006), Business Intelligence é um processo produtivo cuja matéria-prima é a informação e o produto final o conhecimento. Tudo se baseia, portanto, em reunir, arquivar, explorar e conceder dados, transformando-os em informação e conhecimento. Sua função é ajudar os dirigentes a tomarem melhores decisões nos negócios, com informações 
mais precisas, vigentes e expressivas. A Figura 1 representa a estrutura básica conceitual do uso de dados que levam a decisões mais assertivas.

Figura 1 - O Uso de Dados leva a Decisões mais assertivas

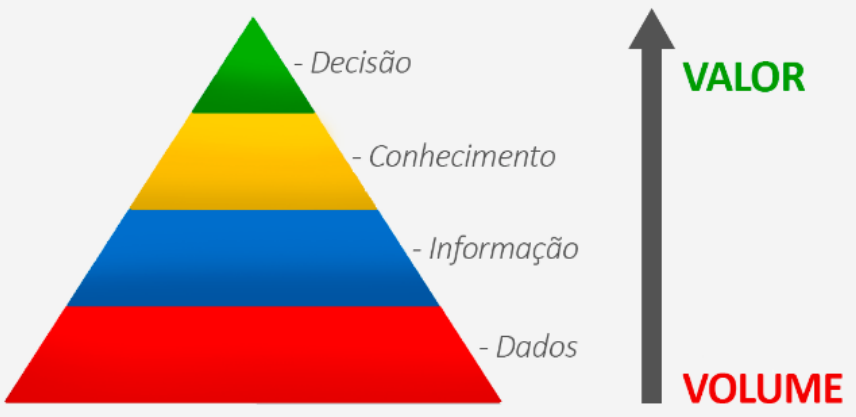

Fonte: Cetax (2019)

Como se percebe pelo que foi referido, a presença de sistemas de BI é de suma importância na realidade de vida das organizações, tendo em vista que de nada adianta armazenar grande quantidade de dados repetitivos, incompletos e espalhados em vários sistemas dentro das corporações. É necessário apurar os que possuem maior impacto, como forma de destacar os mais valiosos, fazendo com que os dados trabalhem de forma eficiente e garantindo vantagem competitiva.

Para atender a esse mercado de inteligência de informações, as empresas de tecnologia devem oferecer sistemas de BI, com várias funcionalidades e com usabilidade, além de oferecer segurança da informação, sobretudo após a Lei Geral de Proteção dos Dados. Empresas como a Alibaba Cloud, Birst, Board International, Domo e a IBM, são algumas das empresas que ofertam o serviço de BI atualmente. De acordo com o relatório da Gartner, o Power BI é pelo $13^{\circ}$ ano consecutivo, líder no Quadrante Mágico de 2020 para Plataformas de Análise e Business Intelligence. (RICHARDSON et al., 2020) 
Figura 1 - Quadrante Mágico para plataformas de Analytics e Business Intelligence

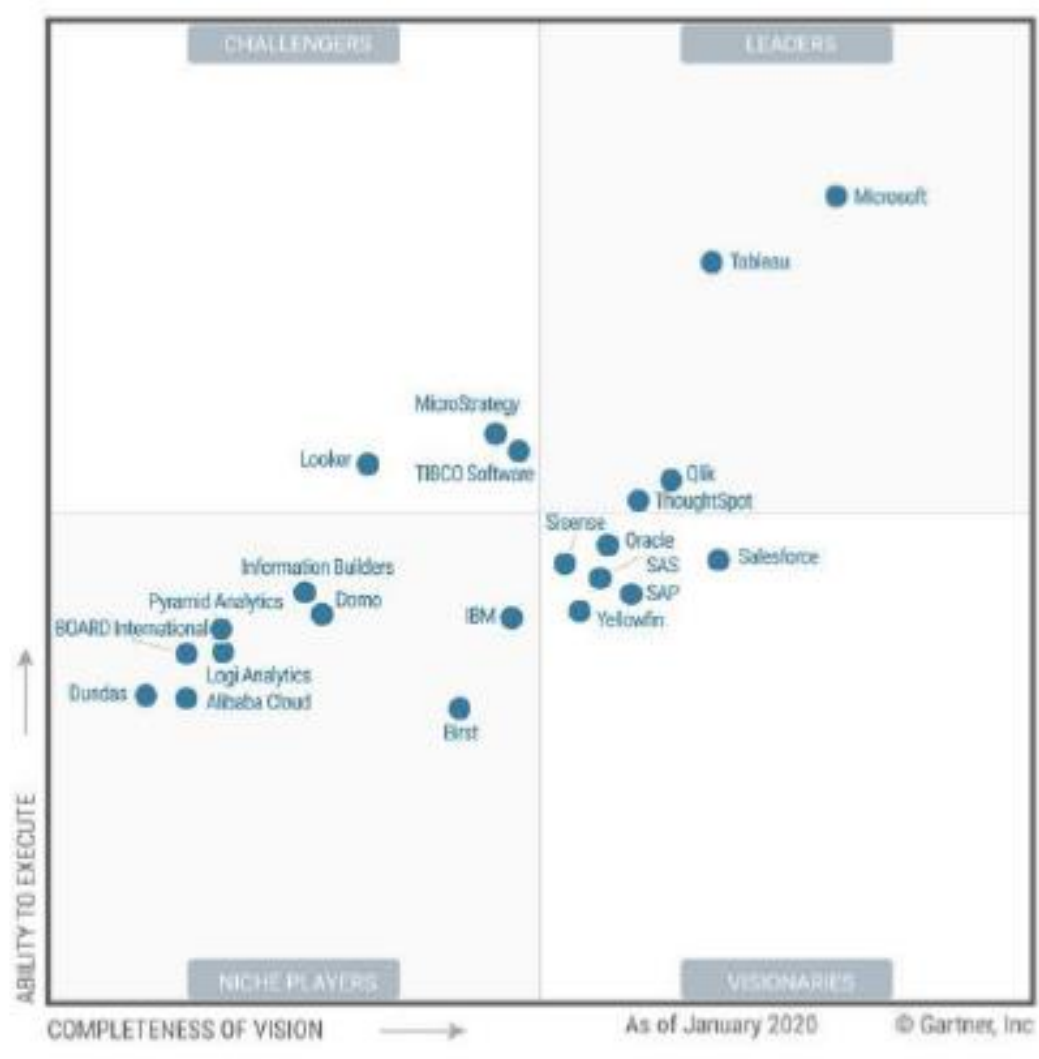

Fonte: Gartner (2020)

\subsection{Power BI}

Conforme, Brito \& Oliveira (2017, p.31) o Power BI é um serviço de Business Intelligence que oferece visualizações interativas com capacidades de self-service, ou seja, os usuários finais podem criar os seus relatórios e painéis sem a necessidade de conhecimentos avançados de banco de dados. O Power BI, lançado em Setembro de 2013, surgiu, inicialmente, com base em três add-ins do Excel (Power Query, Power Pivot e Power View), uma tecnologia de conexão de dados que permite que você descubra, conecte, combine e refine fontes de dados para atender às suas necessidades de análise (MICROSOFT, 2019). 


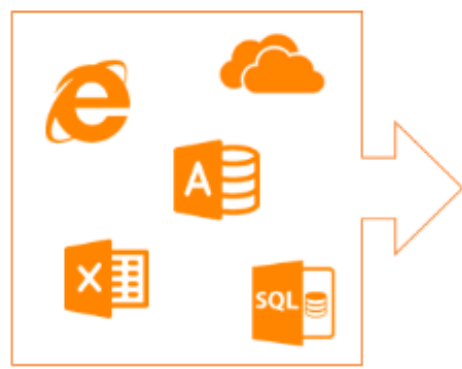

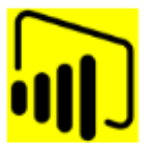

Fonte: Voitto (2019)

A Figura 2 mostra, de forma sucinta, o funcionamento da plataforma Power BI: estabelecendo a conexão com uma ou mais fontes de dados, realizando o tratamento dos dados e, por fim, utilizando componentes gráficos para criação dos painéis. Vale salientar que um projeto em Power BI possui a extensão "pbix", ou seja, pode ser acessado em qualquer outro computador que possua a ferramenta instalada, apesar disso, a maneira mais interessante de compartilhar o projeto é publicá-lo no serviço do Power BI, sendo necessário nesse caso uma conta corporativa. No que tange à tomada de decisão, Coser (2020) verificou que a implantação do sistema de BI auxiliou no fluxo de informações úteis e tempestivas aos usuários, reduzindo a quantidade de informações não interligadas. No setor financeiro, foram obtidos avanços como a possibilidade de melhor visualização e monitoramento do fluxo de caixa, saldos bancários, pagamentos e recebimentos. Já no trabalho de Reginato (2007), destaca-se o efeito do uso das ferramentas do sistema de BI na rotina da contabilidade, que pôde apurar e acompanhar de forma mais próxima eventos como: inadimplência, fretes, comissões, bônus, gastos com desenvolvimento de produtos, transferências de receitas e despesas entre departamentos.

\subsection{Key Performance Indicator (KPI)}

Key Performance Indicator (KPI), ou seja, Indicador-chave de Desempenho, é uma maneira que possibilita a avaliação e o acompanhamento do desempenho de processos da empresa, ou seja, é uma forma de medir se uma ação ou um conjunto de iniciativas está efetivamente atendendo aos objetivos propostos pela organização. Segundo Francischini (2017, p. 6) "indicadores são medidas qualitativas ou quantitativas que mostram o estado de uma operação, processo ou sistema". Ainda segundo o autor, "indicadores de desempenho são medidas que mostram a comparação do que foi realizado pela operação em relação a uma expectativa ou objetivo. Porém, o autor ainda ressalta que "indicadores apontam mas não resolvem problemas". 
Outra definição trazida por Fernandes (2004, p.3), afirma que:

\begin{abstract}
"A atribuição básica de um indicador é retratar, da forma mais transparente possível, uma determinada circunstância que se deseja analisar. O efeito de um indicador é uma reprodução de dado momento, e certificar, perante uma base de medida, aquilo que está sendo realizado ou que foi programado para ser realizado" (FERNANDES, 2004, p. 3).
\end{abstract}

Os KPI são intimamente ligados aos objetivos por um motivo muito simples: são eles que medem a performance de cada um dos objetivos. Francischini (2017, p. 7) menciona que para a construção de um Sistema de Medição de Desempenho, inicialmente, deve-se priorizar "quais são os efeitos mais importantes" e só então implementar indicadores que mensuram o objetivo almejado. Outro ponto mencionado pelo autor é a quantidade de indicadores que serão monitorados, sugerindo "um total de cinco a nove, dependendo do nível hierárquico e/ou funcional do gestor". Ou seja, esse direcionamento faz com que seja observado o que é essencial e circunstancial para o negócio.

Os indicadores de desempenho não possuem uma regra geral para serem formados, porém é desejável que a organização possua um planejamento estratégico definido associado a uma série de características necessárias à facilitação de sua utilização como, por exemplo, simplicidade, praticidade, confiabilidade e realista. Ou seja, é significativo que sejam selecionados como KPI aqueles indicadores cuja meta seja capaz de perfilar a organização com a sua visão e objetivos estratégicos. Portanto, as principais características para aplicação dos KPI de acordo com o Quadro 1 são:

Quadro 1 - Principais Características dos KPIs

\begin{tabular}{|c|c|c|c|c|}
\hline 1 & 2 & 3 & 4 & 5 \\
\hline $\begin{array}{l}\text { Disponibilidade } \\
\text { para ser } \\
\text { mensurado }\end{array}$ & $\begin{array}{l}\text { Importância para a } \\
\text { base do negócio }\end{array}$ & Relevância & $\begin{array}{l}\text { Ajudar em escolhas } \\
\text { inteligentes }\end{array}$ & Periodicidade \\
\hline $\begin{array}{l}\text { Para escolher o } \\
\text { KPI ideal, ele } \\
\text { precisar estar } \\
\text { acessível para } \\
\text { que rejam } \\
\text { avaliados } \\
\text { corretamente. }\end{array}$ & $\begin{array}{l}\text { O KPI mostra que sua } \\
\text { estratégia } \\
\text { surtindo efeito e que o } \\
\text { objetivo principal está } \\
\text { sendo atingido. Caso, } \\
\text { se deseje expandir o } \\
\text { negócio, o } \\
\text { acompanhará } \\
\text { processo esse } \\
\text { certamente, }\end{array}$ & $\begin{array}{l}\text { Uma das maiores } \\
\text { falhas na escolha de } \\
\text { um KPI é escolhê- } \\
\text { lo por vaidade, ou } \\
\text { seja, números que } \\
\text { não apresentam } \\
\text { nenhum resultado. }\end{array}$ & $\begin{array}{l}\text { Dados e informações } \\
\text { formam a base de } \\
\text { uma boa escolha. O } \\
\text { indicador-chave de } \\
\text { desempenho precisa } \\
\text { auxiliar nas escolhas } \\
\text { inteligentes, pois não } \\
\text { adianta ter bons dados } \\
\text { se não forem a base } \\
\text { para as melhores }\end{array}$ & $\begin{array}{l}\text { O KPI precisa ser } \\
\text { mensurado } \\
\text { regularmente, esse } \\
\text { acompanhamento } \\
\text { permite compreender } \\
\text { o que está } \\
\text { funcionando } \\
\text { adequadamente nas } \\
\text { decisões periódicas. }\end{array}$ \\
\hline
\end{tabular}




\begin{tabular}{|l|l|l|l|l|}
\hline & mostrá-lo. & $\begin{array}{l}\text { escolhas } \\
\text { corporação. }\end{array}$ & da \\
\hline
\end{tabular}

Fonte: Adaptado de Marketing de Conteúdo (2019)

O compromisso atribuído aos indicadores é a de proporcionar ao gestor, a compreensão das reais condições por ele realizada, atendendo-lhe na tomada de decisões e assegurando, de forma legítima, a eficiência, eficácia e efetividade dos negócios por ele gerenciados.

\section{Metodologia}

Esta pesquisa trata de um estudo descritivo e quantitativo. Foram coletados dados relacionados ao mix de produtos fornecidos pela empresa, focando na quantidade de produtos vendidos e o faturamento mensal num intervalo de seis meses (de Julho à Dezembro de 2018) com seu acúmulo no final desse período. Vale ressaltar que esses valores correspondem a uma de suas unidades e que serão compilados para a construção do Dashboard. Para a criação do Dashboard, foi utilizado o procedimento metodológico conforme ilustra a Figura 2.

Figura 2 - Metodologia para criação do Dashboard

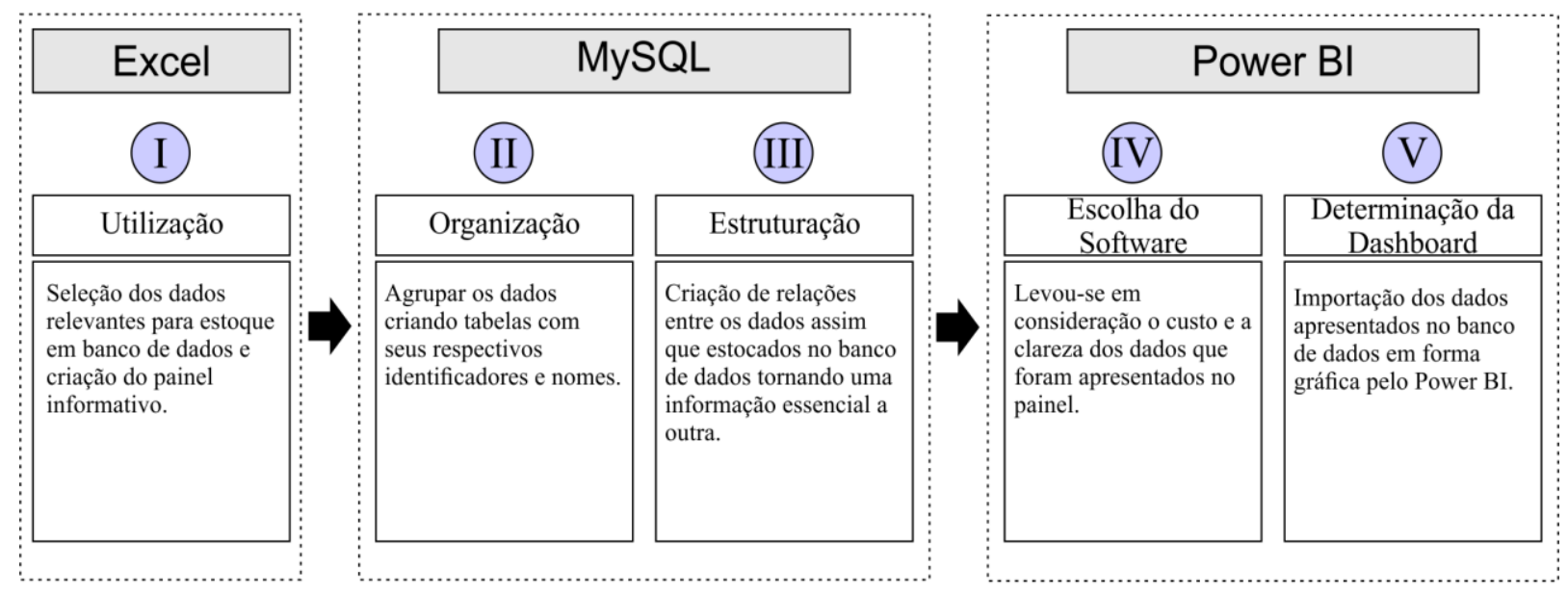

Fonte: Costa (2019)

Como pode ser visualizado da Figura 2, a pesquisa partiu da utilização de dados secundários e, em seguida, iniciou-se a seleção e transformação, ou seja, mudar o formato em que foram adquiridos para formatos em que possam ser trabalhados e, por fim, gerar informações relevantes capazes de identificar fatores que contribuem no desenvolvimento e competitividade da corporação. 
O segundo passo tratou da organização dos dados, com vistas a ganhos de agilidade no processo de tomada de decisão. O terceiro passo foi estruturar esses dados. Isso permitirá ao gestor acompanhar os indicadores-chave como forma de enriquecimento para o negócio viabilizando a identificação de oscilações inesperadas, sem exigir grande tempo de compilação de dados. Assim sendo, foi possível determinar os indicadores realmente necessários à organização.

No quarto passo foi feita a escolha do software para a construção do Dashboard, tendo como critério o baixo custo para criação e modelagem de dados; a clareza das informações, permitindo que todos entendam as ideias de negócios ali demonstradas; e o compartilhamento, oportunizando seu acesso em qualquer local via aplicativo de desktop, serviço SaaS (software como serviço) online e aplicativos móveis do Power BI para dispositivos Windows, iOS e Android.

Finalmente, o último passo tratou da determinação do tipo de Dashboard que seria aplicado. Para tal estudo, foi utilizado o Dashboard operacional, que possibilita o monitoramento de processos de negócios que mudam frequentemente, além do rastreio do desempenho atual de métricaschave e KPI. Em comparação com outros tipos de painéis, os dados são atualizados com muita frequência, às vezes até mesmo minuto a minuto sendo vistos várias vezes ao longo do dia.

\section{Resultados e Discussão}

Para criar o painel, primeiro foram inseridas as fontes de dados em arquivos do Excel no Power $B I$, conforme ilustra a Figura 3.

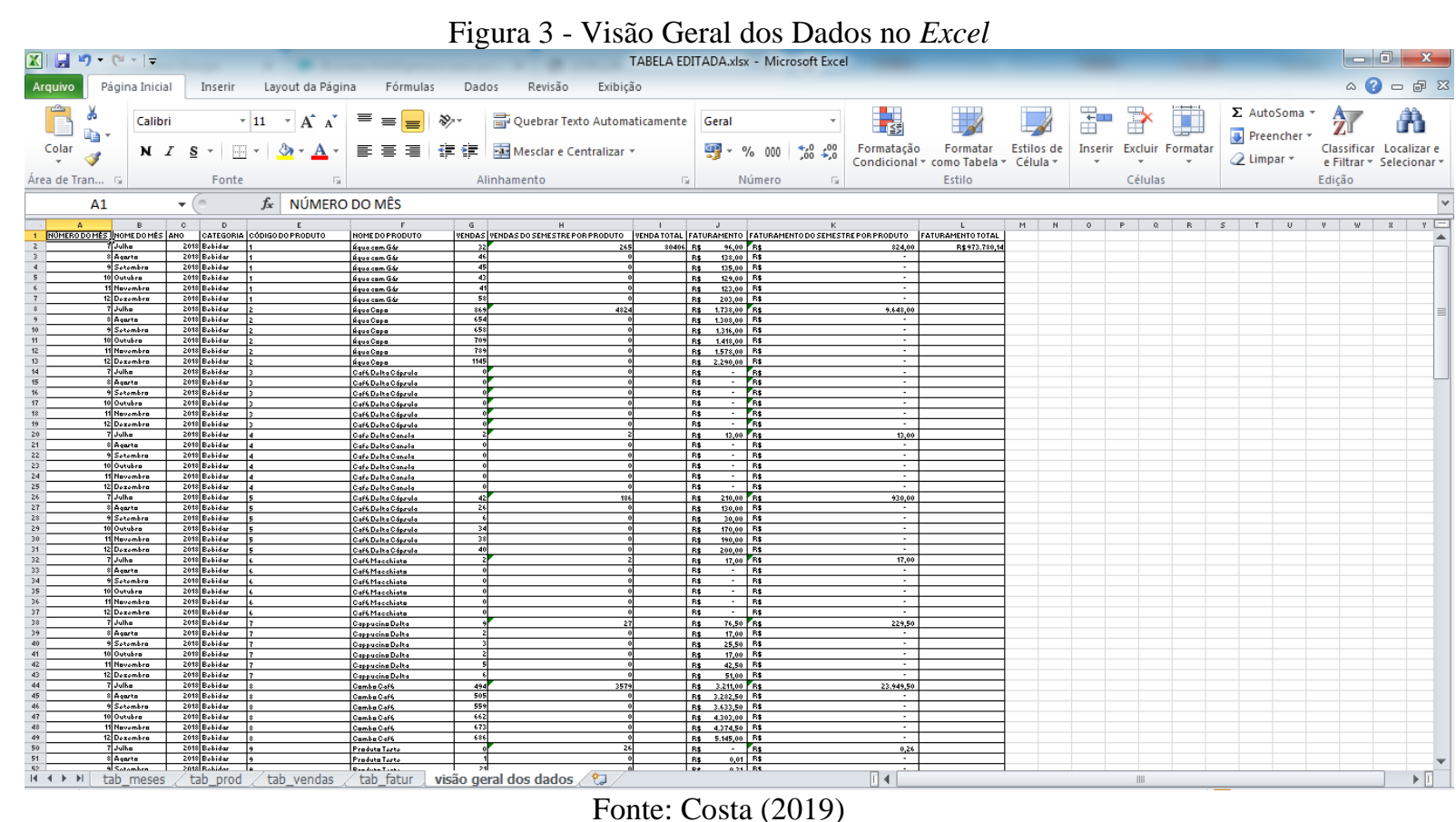

Fonte: Costa (2019) 
Para representação do modelo lógico entre as colunas da tabela, utilizou-se a ferramenta de relacionamentos disponível no Power BI, conforme mostra a Figura 4.

Figura 4 -Relações entre as Tabelas no Power BI

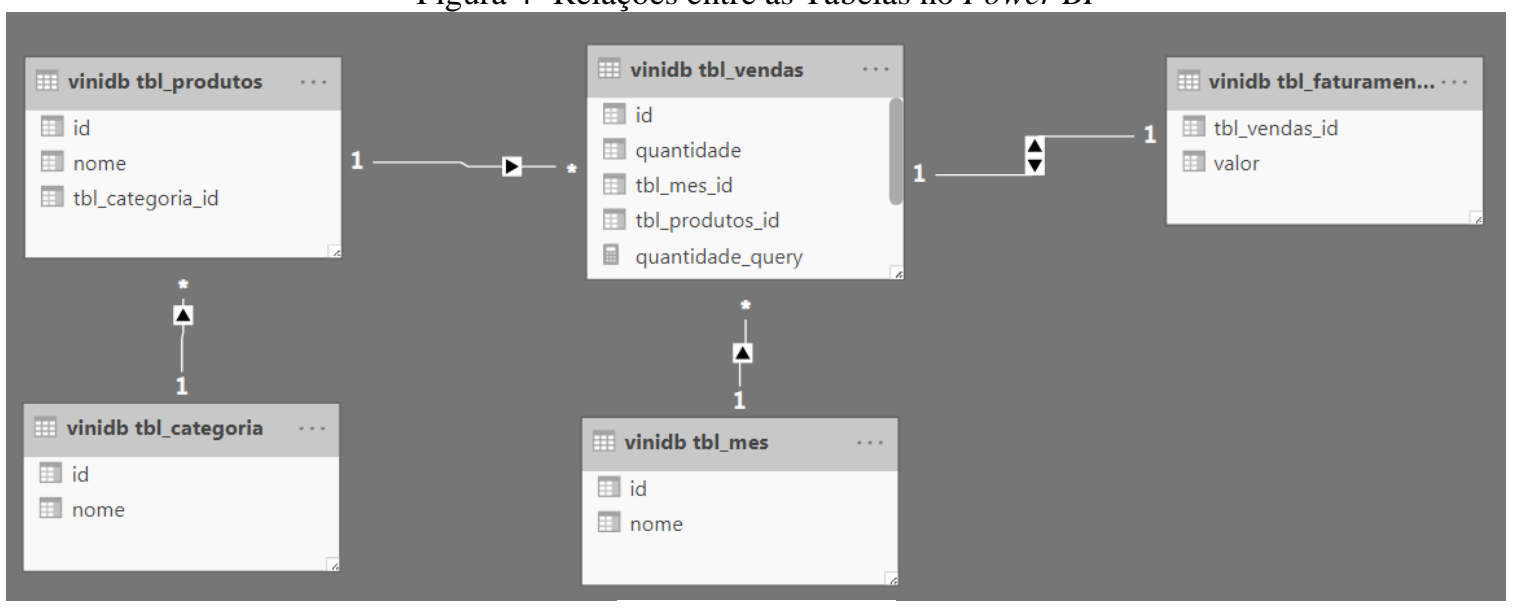

Fonte: Costa (2019)

Quando as informações estão carregadas para o Power BI, ele realizou a identificação automática da carga do banco de dados para criar o relacionamento entre as tabelas. Nesse modelo, não foi preciso informar quais as colunas que ele precisava relacionar, pois ele conseguiu identificar automaticamente os relacionamentos.

Figura 5- Modelo Lógico do Relacionamento no Power BI

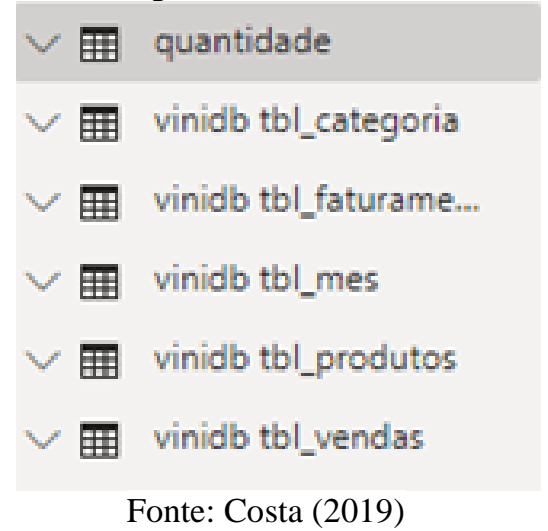

Esse modelo de Relacional foi criado, inicialmente, dentro do banco de dados $M y S Q L$. Como todo o processo está baseado em chaves estrangeiras, então isso resulta em tabelas ligadas por associações de suas chaves únicas.

A seguir, foram criados três filtros de pesquisa, conforme mostra a Figura 6. Como são seis meses, cada mês poderá ser avaliado individualmente ou, ainda, realizar um comparativo com outros meses. O segundo foca na categoria do produto (mix), ou seja, pode ser "Bebidas", "Embalagem" ou "Gelato". Essa seleção dá acesso ao último filtro. O de código do produto, isto 
é, selecionando a categoria, todos os produtos que estão presentes na mesma, aparecerão e poderão ser apurados um ou mais produtos.

Figura 6: Painel de Processo de Filtragem de Dados

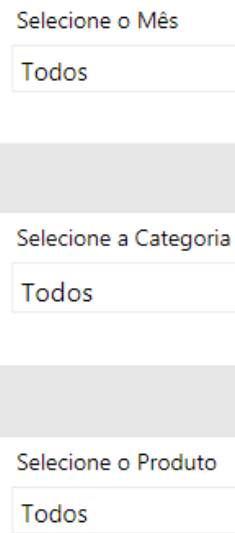

Fonte: Costa (2019)

A Figura 7 mostra o Dashboard construído para a empresa objeto de estudo. Nele é possível ver o quadro de venda total, venda mensal faturamento total, número de produtos vendidos, faturamento mensal, filtro por mês, vendas mensal por mix de produtos e produto com maior número de vendas.

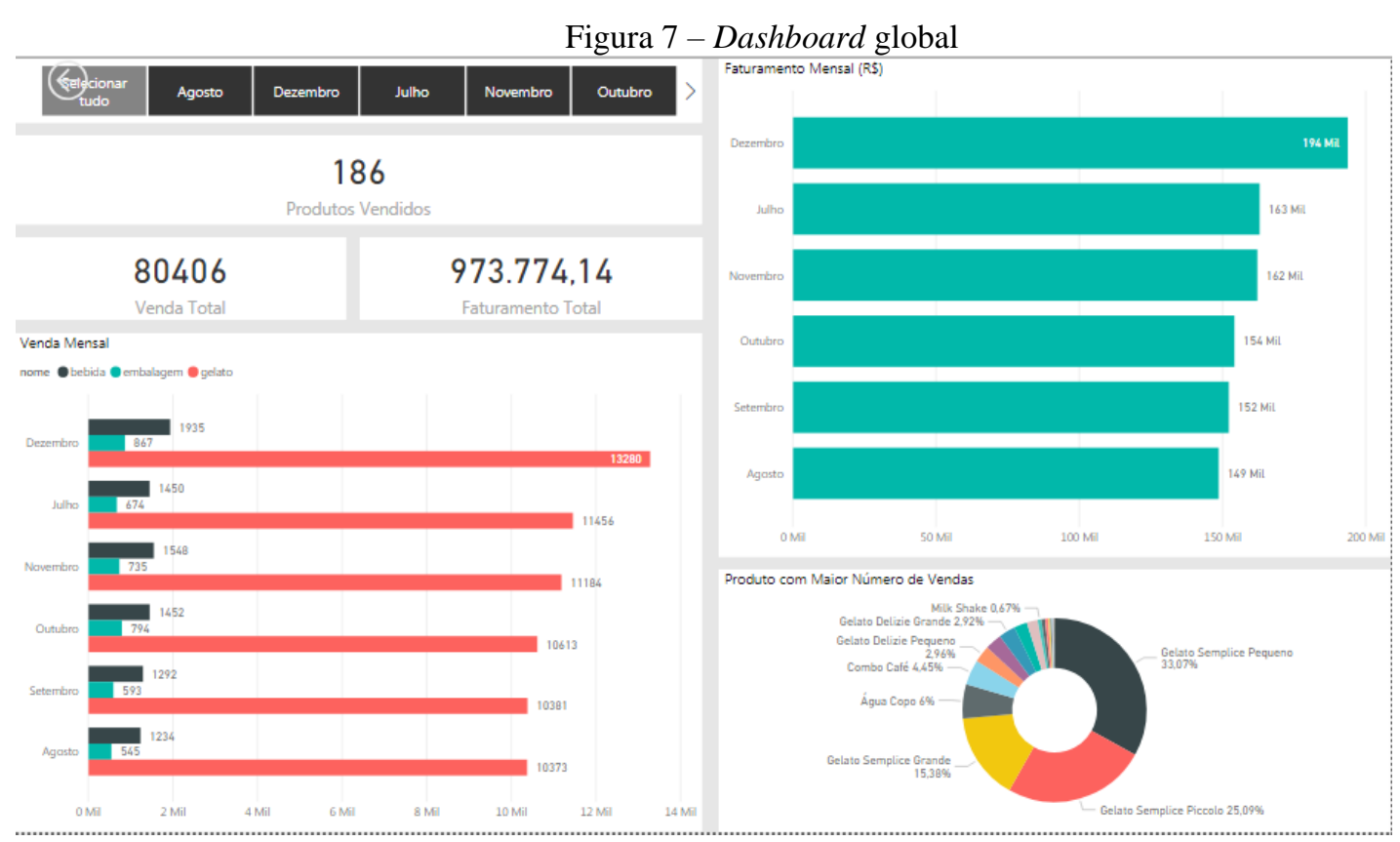

Fonte: Costa (2019) 
Do Dashboard global que fora construído, é possível extrair que Gelato S Pequeno é o que possui o maior faturamento em relação aos demais. Na sua categoria, o faturamento semestral foi de $\mathrm{R} \$ 345.722,00$, o que representa 35,5\% do faturamento geral da empresa e $37,31 \%$ em sua categoria.

Os cartões de indicadores chaves podem ser visualizados na Figura 8. Os parâmetros que foram utilizados como auxílio de KPI são: Venda Total, Faturamento Total e Produtos Vendidos.

Figura 8-Dashboard global

$\begin{array}{ll} & 186 \\ & \\ & \text { Produtos Vendidos } \\ 80406 & 973.774,14 \\ \text { Venda Total } & \text { Faturamento Total }\end{array}$

Fonte: Costa (2019)

Para além da visualização do Dashboard via desktop ou notebook, foi desenvolvida ainda um layout mobile com os KPI e relatórios em tempo real, conforme ilustra a Figura 9.

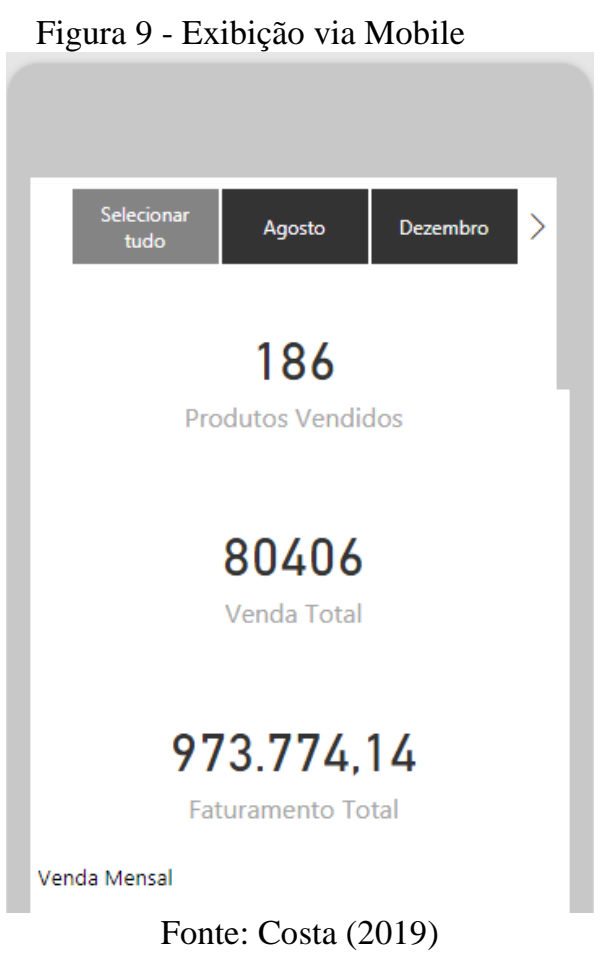

\section{Considerações Finais}


Esse trabalho teve como objetivo a implantação de Business Intelligence, a partir do Power BI, em uma empresa de gelatos. Através dos indicadores de desempenho disponibilizados no Dashboard desenvolvido, foi possível acompanhar as variações de vendas e faturamentos da organização, bem como, futuramente, serem tomadas decisões.

Diante dos resultados obtidos no desenvolvimento deste trabalho, avalia-se positivamente a arquitetura de solução para administração das informações da empresa, demonstrando que seu uso possibilitará benefícios no dia-a-dia da organização relacionados à gestão dos dados como, por exemplo, economia de tempo e esforço no processo de tomada de decisão. Outra vantagem que se deve evidenciar é a facilidade em responder auditorias internas e comprovar os indicadores da corporação e cumprindo assim, os objetivos abordados neste trabalho.

\section{REFERÊNCIAS}

CETAX. Business Intelligence - BI: Tudo o que você precisa saber!. Disponível em: https://www.cetax.com.br/business-intelligence-tudo-o-que-voce-precisa-saber/. Acesso em: 30 abr. 2021

COSER, T. Contabilidade de gestão em sintonia com o Business Intelligence (BI): estudo de caso. Brazilian Journals of Business, Curitiba, v. 2, n. 3, p. 3093-3112, 2020.

COSTA, V.N.L. Aplicação de Dashboards para monitoramento de indicadores de desempenho em uma empresa do ramo alimentício. Trabalho de Conclusão de Curso, 2019.

FERNANDES, D.R. Uma contribuição sobre a construção de indicadores e sua importância para a gestão empresarial. Revista da FAE, 7(1), p.1-18, 2004.

FRANCISCHINI, A. S. N.; FRANCISCHINI, P. G. Indicadores de desempenho: dos objetivos à açãoMétodos para elaborar KPIs e obter resultados. Rio de Janeiro: Alta books, 2017.

LAUDON, Jane P.; Laudon, Kenneth C. Sistemas de informações gerenciais. $11^{a}$. Ed. São Paulo- SP: Pearson Education do Brasil Ltda., 2014. 506 p. ISBN 978-85-4301-507-1.

MICROSOFT. Business Intelligence como nunca. Disponível em: https://powerbi.microsoft.com/pt-br/. Acesso em: 30 abr. 2021

SEZÕES, Carlos; OLIVEIRA, José; BAPTISTA, Miguel. BUSINESS INTELLIGENCE. Porto: SPI - Sociedade Portuguesa de Inovação, 2006.

REGINATO, L; NASCIMENTO, A.M. Um estudo de caso envolvendo Business Intelligence como instrumento de apoio à controladoria. Revista Contabilidade \& Finanças, 18(spe), 69-83, (2007).

RICHARDSON, James; et. al. Magic quadrant for analytics and business intelligence platforms. 2020

The 2018 Global Data Management Benchmark Report, Experian. 2018 global data management benchmark report. Disponível em: https://www.edq.com/resources/data-management-whitepapers/2018-global-datamanagement-benchmark-report/. Acesso em: 30 abr. 2021. 
The 2019 Global Data Management Research, Experian. The 2019 Global Data Management Research. Disponível em: https://www.edq.com/resources/data-management-whitepapers/2019-global-data-managementresearch/. Acesso em: 30 abr. 2021.

TURBAN, E. Business intelligence: um enfoque gerencial para a inteligência do negócio. São Paulo: Bookman, 2009. 